\title{
Edge-to-edge mitral valve repair with transapical neochord implantation
}

Andrea Colli, MD, PhD, ${ }^{\mathrm{a}}$ Laura Besola, MD, ${ }^{\mathrm{a}}$ Eleonora Bizzotto, MD, ${ }^{\mathrm{a}}$ Paolo Peruzzo, PhD, ${ }^{\mathrm{b}}$

Demetrio Pittarello, MD, ${ }^{a}$ and Gino Gerosa, $\mathrm{MD}^{\mathrm{a}}$

From the ${ }^{\mathrm{a} D e p a r t m e n t}$ of Cardiac Thoracic and Vascular Sciences, and ${ }^{\mathrm{b}}$ Cardiovascular Fluid Dynamics Laboratory HER, Department of Civil, Environmental and Architectural Engineering, University of Padua, Padua, Italy.

Funding Sources: None.

Disclosures: A.C., L.B., E.B., and G.G. received travel grants from NeoChord, Inc. A.C. and D.P. have proctored for NeoChord, Inc. P.P has nothing to disclose with regard to commercial support.

Received for publication Oct 29, 2017; revisions received Jan 10, 2018; accepted for publication Feb 2, 2018; available ahead of print March 3, 2018.

Address for reprints: Andrea Colli, MD, PhD, FECTS, Department of Cardiology, Thoracic and Vascular Sciences, University of Padua, via Giustiniani, 2, 35128 Padova, Italy (E-mail: colli.andrea.bcn@gmail.com).

J Thorac Cardiovasc Surg 2018;156:144-8

$0022-5223 / \$ 36.00$

Copyright $(2) 2018$ by The American Association for Thoracic Surgery

https://doi.org/10.1016/j.jtcvs.2018.02.008

$\checkmark$ Video clip is available online.

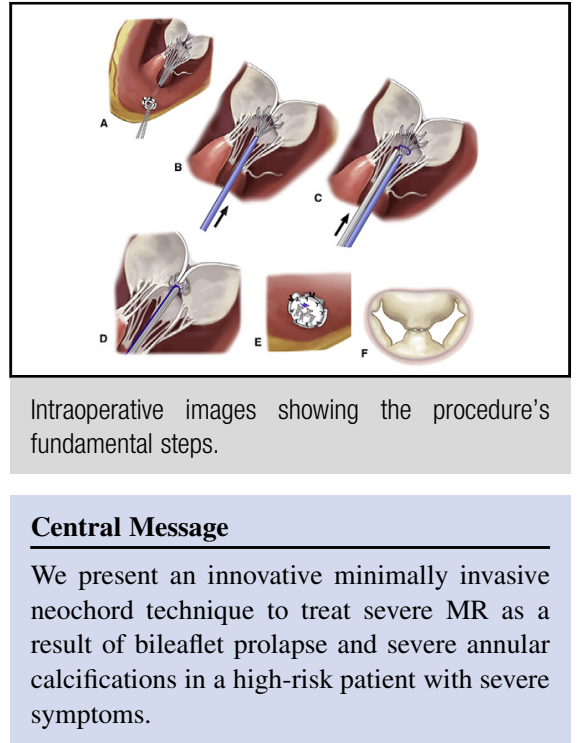

See Editorial Commentary page 149
The neochord mitral valve repair procedure has proved its safety and efficacy in patients with isolated P2 segment flail and prolapse. ${ }^{1-4}$ We present images of a complex mitral valve anatomy treated with transapical edge-toedge mitral valve repair with neochord implantation as a bailout procedure in a 72-year-old male patient considered a high-risk (euroSCORE II of $6.7 \%$ ) and frail surgical candidate who was not considered eligible for any other approved transcatheter therapy. Procedure validation and technical refinements were previously performed in an ex vivo pulsatile heart model (Figure 1 and Video 1). Echocardiography demonstrated severe MR located both central and at the medial commissure as a result of bileaflet prolapse with severe mitral annular calcifications (Figure 2 and Video 2). The procedure was performed with the patient under general anesthesia through standard posterolateral ventricular access under transesophageal echocardiographic guidance. In total, 3 neochords were implanted on the posterior (P2-P3) and 3 on the anterior leaflet (A2-A3). The coaptation of the 2 leaflets was achieved by putting tension on all the neochords in conjunction with the use of a transapical pediatric tourniquet. Once a stable coaptation was achieved, we tightened all the neochords at the base of the ventricular edge of the leaflets with a ligating loop system that was advanced over the tourniquet under echocardiographic guidance. Once the loop was secured, the tourniquet was removed, ventricular purse-strings were closed, and all the neochords and the distal end of the loop were fixed on the epicardial surface in common fashion as for a standard neochord repair procedure (Figure 3).

The patient was discharged home. At 1-month follow-up, he was free of symptoms (New York Heart Association functional class I) and had mild to moderate MR, as confirmed by echocardiography (Figure 4). Future technique refinements and dedicated additional devices for tensioning and final fixation will be required to improve reproducibility and durability. 


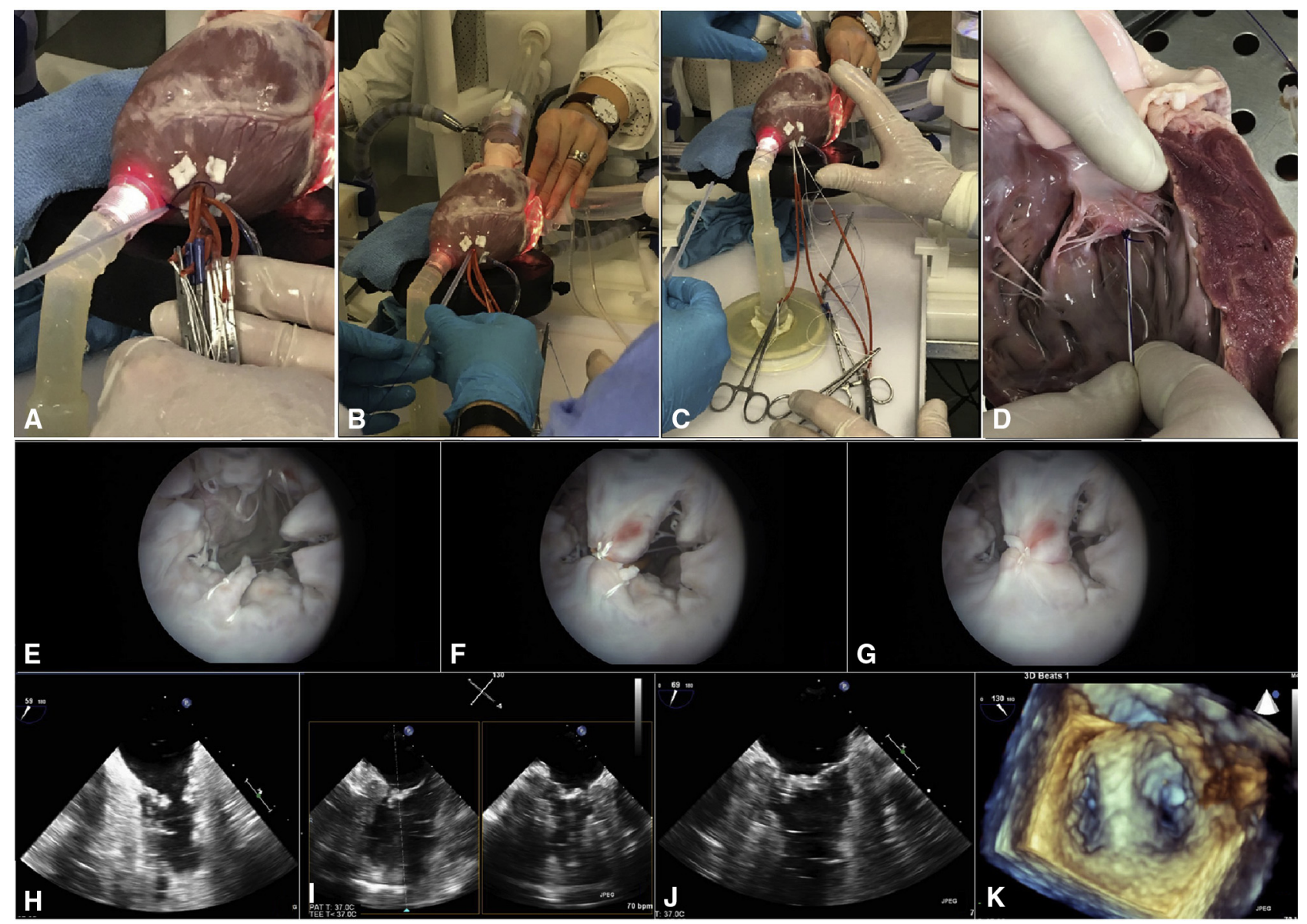

FIGURE 1. A, All the neochords implanted were passed through a ligating loop (Surgitie 0; Medtronic, Minneapolis, Minn). B, The knot pusher of the ligating loop was advanced under echocardiographic guidance. C, The knot pusher and tensioning tourniquet were removed. D, Edge-to-edge neochord fixation was verified after the procedure. E, Direct visualization of the mitral valve was recorded with a fiberscope inserted in the left atrium to show implantation of the neochords. F, Direct visualization of the edge-to-edge repair was created by tensioning all the neochords together over a tourniquet. G, Direct visualization of the final aspect of the edge-to-edge repair. H, Two-dimensional epicardial echocardiography showing the flail of the posterior leaflet. I, Two-dimensional epicardial echocardiography showing the implanted neochords fixed over the tourniquet. J, Two-dimensional epicardial echocardiography showing the classic edge-to-edge leaflet fixation. $\mathrm{K}$, Three-dimensional echocardiography showing the double-orifice image of the mitral valve.

\section{References}

1. Colli A, Manzan E, Zucchetta F, Bizzotto E, Besola L, Bagozzi L, et al. Transapical off-pump mitral valve repair with Neochord implantation: early clinical results. Int J Cardiol. 2016;204:23-8.

2. Colli A, Bizzotto E, Pittarello D, Gerosa G. Beating heart mitral valve repair with neochordae implantation: real-time monitoring of haemodynamic recovery. Eur J Cardiothorac Surg. 2017;52:991-2.
3. Colli A, Manzan E, Zucchetta F, Sarais C, Pittarello D, Gerosa G. Feasibility of anterior mitral leaflet flail repair with transapical beating-heart neochord implantation. JACC Cardiovasc Interv. 2014;7:1320-1.

4. Colli A, Bizzotto E, Manzan E, Besola L, Pradegan N, Bellu R, et al. Patient-spe cific ventricular access site selection for the neochord mitral valve repair procedure. Ann Thorac Surg. 2017;104:e199-202. 


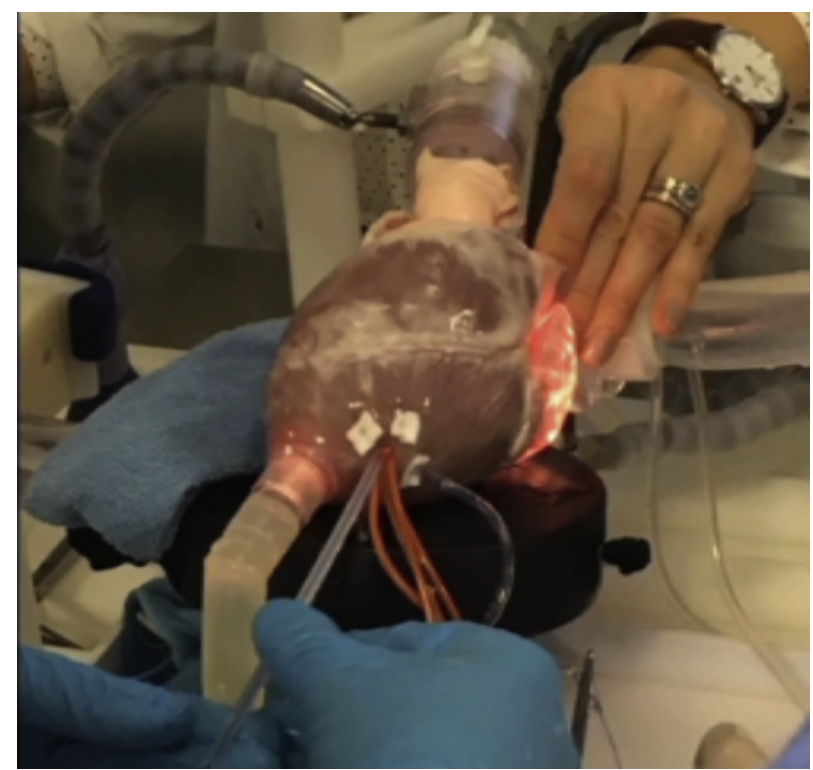

VIDEO 1. Ex vivo pulsatile heart model procedure simulation. Video available at: http://www.jtcvsonline.org/article/S0022-5223(18)30356-8/fulltext.
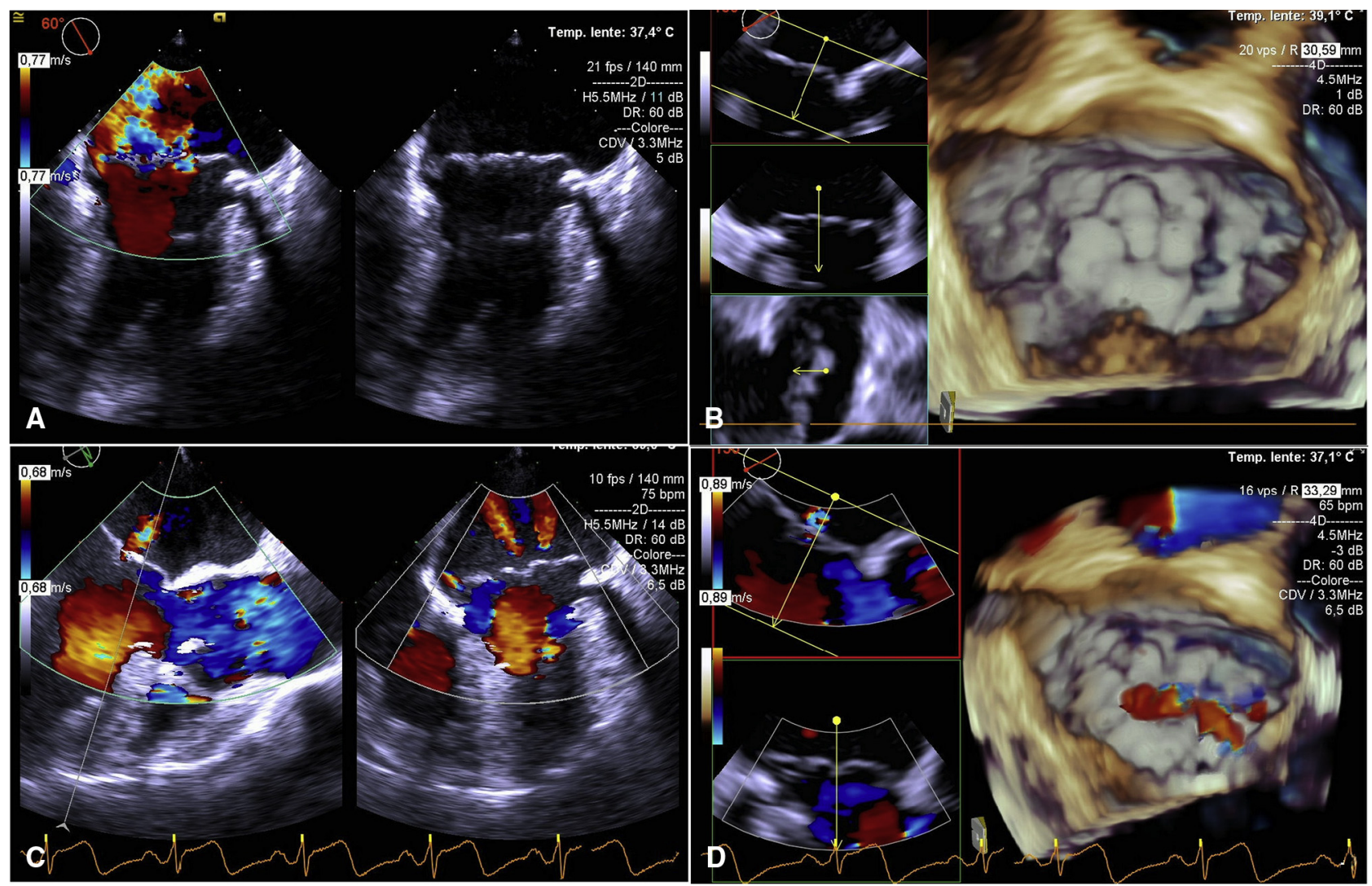

FIGURE 2. A, Two-dimensional color Doppler transesophageal echocardiography showing severe mitral regurgitation. B, Three-dimensional echocardiography demonstrating the presence of partial severe calcification of the annulus and complex leaflet anatomy. C, Postoperative 2-dimensional color Doppler echocardiography confirming the presence of mild mitral regurgitation. D, Three-dimensional color Doppler echocardiography showing the presence of a mild mitral regurgitation. 


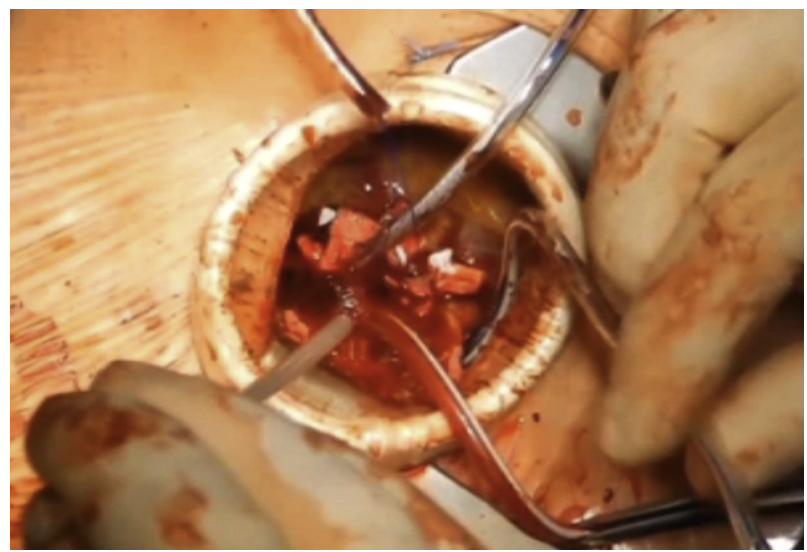

VIDEO 2. Transapical edge-to-edge mitral valve repair with neochord implantation surgical procedure and echocardiographic evaluation. $2 D$, Two-dimensional; 3D, three-dimensional; TEE, transesophageal echocardiography. Video available at: http://www.jtcvsonline.org/article/S0022-5223(18)30356-8/ fulltext.
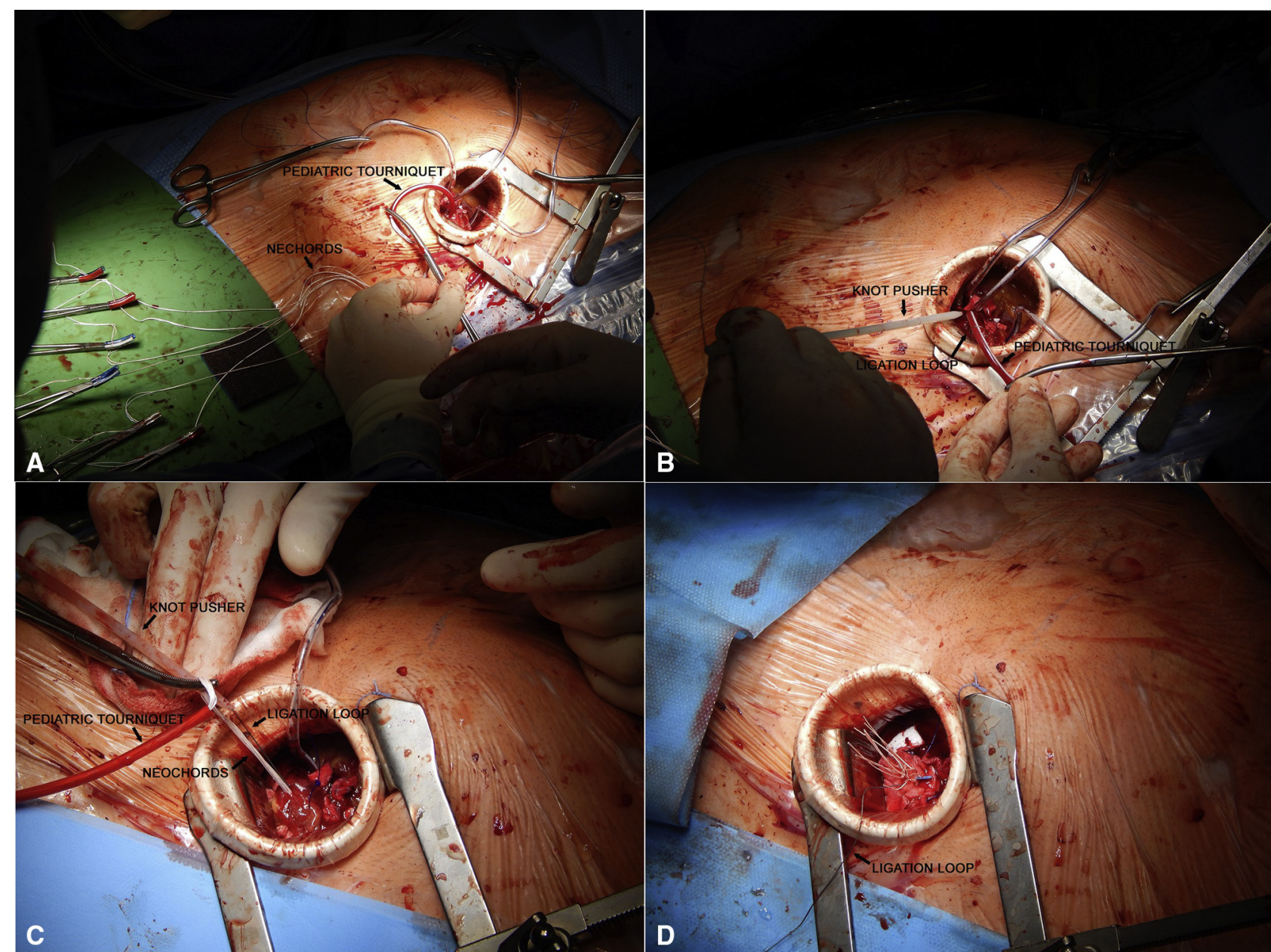

FIGURE 3. A, All implanted neochords were passed through a pediatric tourniquet and tensioned. B, The ligating loop system was advanced over the tourniquet. C, All neochords and the ligating loop were fixed, and the pediatric tourniquet was removed. D, The neochords and the ligating loop were passed through a single pledget and fixed on epicardial surface as usual for neochord repair. 


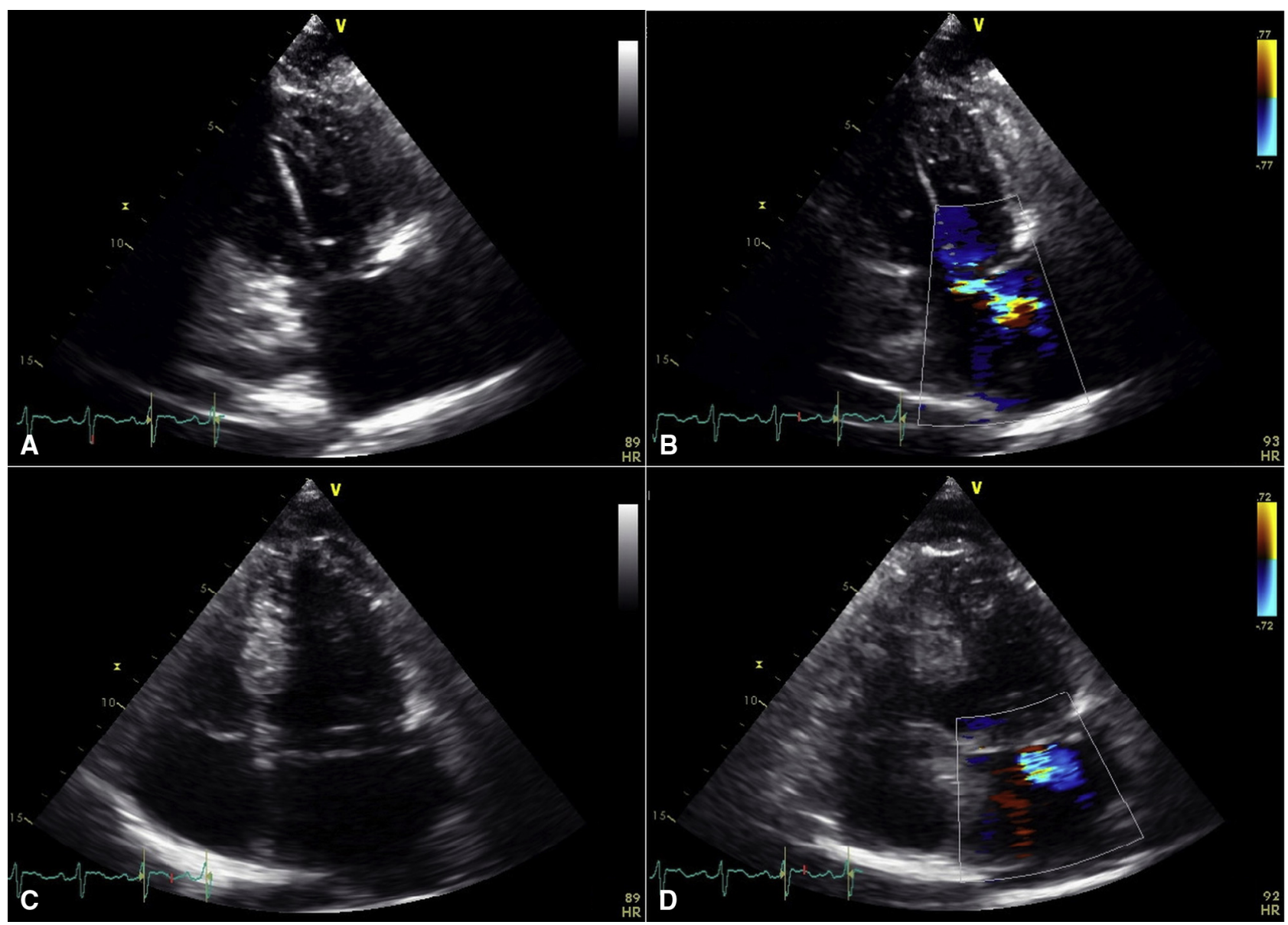

FIGURE 4. A, Postoperative 2-chamber view transthoracic 2-dimensional echocardiography showing the implanted neochords in the left ventricle. B, Postoperative 2-chamber view color Doppler transthoracic 2-dimensional echocardiography showing the residual mitral regurgitation. C, Postoperative 4-chamber view transthoracic 2-dimensional echocardiography showing an appropriate plane of coaptation. D, Postoperative 4-chamber view color Doppler transthoracic 2-dimensional echocardiography showing the residual mitral regurgitation. 